\title{
Synthesis of pentaerythritol adipate ester-based Zinc Alkoxide and its thermal stability on PVC
}

\begin{abstract}
A new pentaerythritol adipate ester-based zinc alkoxide (PAE-Zn) was synthesized through an alcohol-exchange reaction. The thermal stability of PAE-Zn in PVC (poly vinyl choride) was examined by conductivity and thermal aging tests. The results showed that the PVC stabilized with PAE-Zn has a good initial color and excellent long-term thermal stability. A synergistic effect of PAE-Zn with calcium stearate $\left(\mathrm{CaSt}_{2}\right)$ and zinc stearate $\left(\mathrm{ZnSt}_{2}\right)$ on PVC thermal stability was also been tested. It showed that the complex of PAE- $\mathrm{Zn} / \mathrm{CaSt}_{2} / \mathrm{ZnSt}_{2}$ had a better integrated effect on inhibiting the color change of PVC.
\end{abstract}

Keywords: PVC, pentaerythritol adipate ester-based zinc alkoxide, thermal stabilizer

\author{
Volume 2 Issue I - 2018 \\ Yuepeng Li,' Tianbao Dong,' Wenyuan Han,' \\ Degang Li,' Lipeng Zhang,' Yali Zhang,' \\ Shouyu Tang ${ }^{2}$ \\ 'School of Chemistry and Chemical Engineering, Shandong \\ University of Technology, China \\ ${ }^{2}$ Shandong Huike Additives Co Ltd, China
}

\begin{abstract}
Correspondence: Degang Li, School of Chemistry and Chemical Engineering, Shandong University of Technology, Zibo 255000, PR China, Tel +86 18766957507, Email Idg@sdut.edu.cn
\end{abstract}

Received: October 30, 2017 | Published: January 22, 2018

\section{Introduction}

Because of the excellent corrosion resistance, antiflaming and electrical insulation, PVC (poly vinyl choride) has become one of the five commonly used plastics in the world. ${ }^{1,2}$ However, PVC has significant defects due to its quick decomposition at temperature higher than $130^{\circ} \mathrm{C}^{3-5}$ This process results in a significant change in color, reducing the mechanical properties and the generated $\mathrm{HCl}$ exacerbates the decomposition of PVC, so the usage of PVC thermal stabilizers is inevitable. ${ }^{4,6}$ Our group had synthesized pentaerythritolbased zinc alkoxide (PE-Zn) as a thermal stabilizer. ${ }^{7} \mathrm{PE}-\mathrm{Zn}$ has outstanding performances in terms of color stability and long-term stability of rigid PVC. However, most of the alkoxide have high melting point and poor compatibility with PVC, which significantly restrict their wide applications. In order to decrease the melting point of polyols-based metal alkoxide, an ester group, such as stearic acid, was grafted onto the polyols to obtain pentaerythritol stearate esterbased zinc alkoxide. ${ }^{8}$

In this study, a new ester-based metal alkoxide, pentaerythritol adipate ester-based zinc alkoxide (PAE-Zn) was synthesized, which had low melting point and good compatibility with PVC. The thermal stabilizing tests showed that PAE-Zn stabilized PVC had both a good initial color and an excellent long-term thermal stability.

\section{Experimental}

\section{Materials}

Zinc acetate, ethanol, adipic acid, pentaerythritol, phosphoric acid, cyclohexane, calcium stearate and zinc stearate were all analytical reagents. PVC resin (type SG-5, average degree of polymerization is 1005 and viscosity number is 67) was obtained from China Petrochemical Qilu Limited Co., Zibo, China. Other thermal additives were kindly supplied by Shandong Huike Additives Co.Ltd., Zibo, China.

\section{Preparation of PAE-Zn}

Adipic acid and pentaerythritol in a molar ratio of 1:2 were added into a mixer and stirred for $5 \mathrm{~min}$, and then the mixture was placed in a three-necked flask equipped with a condenser-Allihn type and a water separator. The appropriate amount of phosphoric acid was added into the flask as a catalyst and cyclohexane as a watering agent. The esterification reaction temperature was kept at $170^{\circ} \mathrm{C}$ until there was no water generated (about $4 \mathrm{~h}$ ). The pentaerythritol adipate ester (PAE) was obtained after the residual cyclohexane was removed by vacuum distillation.

PAE and zinc acetate in a molar ratio of 2:1 were added into a three-necked flask. Excess ethanol was added and the flask was heated to $160^{\circ} \mathrm{C}$ for reaction of $4 \mathrm{~h}$. After the ethanol was fully evaporated, PAE-Zn was obtained.

\section{FTIR analysis}

PAE-Zn was characterized by FTIR spectroscopy using the $\mathrm{KBr}$ disc method. The range of the spectrum wavelength was $400-4000 \mathrm{~cm}^{-}$ ${ }^{1}$ with a scanning rate of $128 \mathrm{~min}^{-1}$ and a resolution of $4 \mathrm{~cm}^{-1}$.

\section{Elemental analysis}

Elemental analysis (Vario ELcube) was used to determine, hydrogen, and oxygen contents of the PAE-Zn samples.

\section{Thermal aging test}

The PVC blends were prepared by intensively mixing 100.0phr of PVC, 2.0phr of acrylic copolymer (ACR), 1.6phr of stearic acid, $10.0 \mathrm{phr}$ of $\mathrm{CaCO}_{3}, 4.0 \mathrm{phr}$ of $\mathrm{TiO}_{2}$ 8.0phr of DOP, and 0phr or $4 \mathrm{phr}$ of thermal stabilizers in a high-speed stirring for about $3 \mathrm{~min}$. The $\mathrm{PVC}$ blends were milled using an open twin roller at $180^{\circ} \mathrm{C}$ for $5 \mathrm{~min}$. The thickness of the drawn-out sheets was controlled at $1.0 \pm 0.1 \mathrm{~mm}$. Thermal aging test: The PVC sheets were cut into small pieces $(10 \mathrm{~mm} \times 10 \mathrm{~mm})$. These small sheets were subjected to static thermal aging test according to the ISO standard. ${ }^{8}$ The temperature of the thermal aging test box was kept at $180 \pm 1^{\circ} \mathrm{C}$.

\section{Conductivity test}

The PVC sheets were cut into small flakelets with a total weight 
of $2 \mathrm{~g}$, and then they were put into home-made reaction vessels at $\mathrm{N}_{2}$ atmosphere. A $60 \mathrm{~mL}$ deionized water, containing dissolved $\mathrm{HCl}$ originated from the decomposition of $\mathrm{PVC}$, was conducted the conductivity measurement.

\section{Results and discussion}

Figure 1 shows the FTIR spectra of PAE-Zn. The strong peak at $3405 \mathrm{~cm}^{-1}$ is the characteristic absorbance of $-\mathrm{OH}$, which suggests plenty of hydroxyl group in PAE-Zn. The peak at $1720 \mathrm{~cm}^{-1}$ is referring to ester carbonyl structure $\mathrm{C}=\mathrm{O}$ stretching vibration. The peak at $669 \mathrm{~cm}^{-1}$ is ascribed to the $\mathrm{Zn}-\mathrm{O}$ bond ${ }^{9}$ in PAE-Zn.

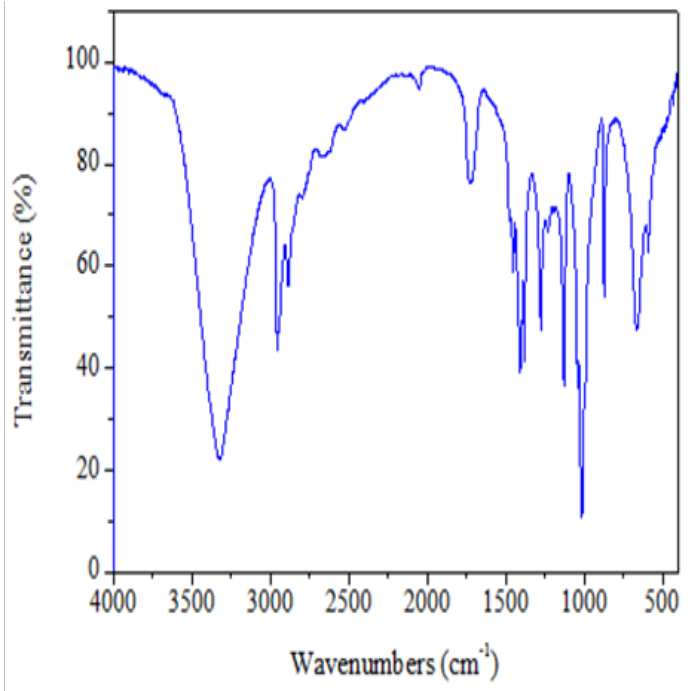

Figure I FTIR spectrum of PAE-Zn.

Table 1 lists the contents of the $\mathrm{C}, \mathrm{H}, \mathrm{O}$ and $\mathrm{Zn}$ elements. According to the theoretical basis and experimental results, the structure of PAE$\mathrm{Zn}$ can be inferred and shown in Figure 2. When the PVC is heated to a high temperature, the unstable chloride atom will be removed together with the adjacent hydrogen, and the conjugated double bonds are generated. With the duration of the heating time, the number of conjugated double bonds increases. Meantime, the PVC turned gradually from white to brown, and at the end, it becomes black. The change in PVC color can indicate the degradation of PVC. Figure 3 illustrates the images of PVC samples heated at $180^{\circ} \mathrm{C}$ for different periods of time. The initial color of pure PVC is light brown, and the color turns to brown after $10 \mathrm{~min}$. The initial color of the PVC sheets containing $2 \mathrm{phr} \mathrm{CaSt}_{2}$ and $2 \mathrm{phr} \mathrm{ZnSt}_{2}$ (the commercial used thermal stabilizer of PVC) was almost white and began to change at $20 \mathrm{~min}$, and turned into dark brown quickly at $30 \mathrm{~min}$. It suggests that $\mathrm{CaSt}_{2} /$ $\mathrm{ZnSt}_{2}$ is an excellent thermal stabilizer for PVC, which has excellent initial thermal stability. But it is a quite short thermal stability, because of the generation of zinc dichloride $\left(\mathrm{ZnCl}_{2}\right)$ during the stabilizing process of $\mathrm{ZnSt}_{2} . \mathrm{ZnCl}_{2}$ is a strong Lewis acid, which can catalyze the dehydrochlorination of the PVC and make the PVC turn into black quickly. ${ }^{10-14}$ This phenomenon is called the "zinc burning".

Table I The element content of PAE-Zn

\begin{tabular}{lllll}
\hline & C & H & O & Zn \\
\hline Theoretical value & $42.74 \%$ & $6.33 \%$ & $33.77 \%$ & $17.16 \%$ \\
Elemental analysis date & $42.41 \%$ & $6.22 \%$ & $33.83 \%$ & $17.54 \%$ \\
\hline
\end{tabular}

The PVC with 4 phr PAE-Zn doesn't turn into complete black until $120 \mathrm{~min}$, indicating that PAE-Zn is a highly efficient thermal stabilizer in inhibiting the degradation of PVC. The adipic acid ester based functional groups would possibly make the PAE-Zn have a good compatibility with PVC and can greatly improve the stability of PVC. However, the initial color of PVC stabilized with PAE-Zn is not as white as that of $\mathrm{CaSt}_{2} / \mathrm{ZnSt}_{2}$. Meanwhile the synergistic effect of PAE$\mathrm{Zn}$ and $\mathrm{CaSt}_{2} / \mathrm{ZnSt}_{2}$ was also investigated. It can be seen from Figure 3 that the color of the PVC containing $1 \mathrm{phr} \mathrm{ZnSt}_{2}+1 \mathrm{phr} \mathrm{CaSt}_{2}+2 \mathrm{phr}$ PAE-Zn not only presents a quite white in initial color, but also has an excellent long-term stability. This indicated that PAE-Zn and $\mathrm{CaSt}_{2} /$ $\mathrm{ZnSt}_{2}$ mixture had a pronounced synergetic effect on the stability of PVC. Figure 3 shows that there is no "zinc-burning" phenomenon for the PVC stabilized with the mixture of PAE-Zn and $\mathrm{CaSt}_{2} / \mathrm{ZnSt}_{2}$. A reasonable explanation is that $\mathrm{ZnCl}_{2}$ generated during the process of $\mathrm{ZnSt}_{2}$ replacing the active chloride atom of $\mathrm{PVC}$ or neutralizing $\mathrm{HCl}$ might be cheated by $-\mathrm{OH}$ of PAE- $\mathrm{Zn}$. In conclusion, PAE- $\mathrm{Zn}$ is an excellent thermal stabilizer for PVC.

Figure 4 shows curves of conductivity vs. time for different PVC samples. The stability time $\left(\mathrm{T}_{\mathrm{s}}\right)$ of pure PVC is only $20 \mathrm{~min}$, which demonstrates the poor thermal stability of pure PVC. The addition of $\mathrm{Ca} / \mathrm{ZnSt}_{2}$ extends the $\mathrm{T}_{\mathrm{s}}$ of PVC to $32 \mathrm{~min}$. The $\mathrm{T}_{\mathrm{s}}$ of PVC stabilized with PAE- $\mathrm{Zn}$ is $52 \mathrm{~min}$, the biggest among the four PVC samples, which shows that the addition of PAE-Zn can prolong the long-term thermal stability of PVC obviously. However, the conductivity of PVC stabilized with PAE-Zn increases a little when the PVC was heated for about $20 \mathrm{~min}$. The increasing conductivity reveals the fact that the PVC begins to decompose. The results agree with that of thermal aging test, demonstrating that PVC stabilized with PAE-Zn has long-term thermal stability, but has common initial color stability. In order to improve the initial color, PAE-Zn was used together with $\mathrm{Ca} / \mathrm{ZnSt}_{2}$ demonstrate excellent initial color. Figure 4 shows that the PVC stabilized with the mixture of PAE-Zn and $\mathrm{CaSt}_{2} / \mathrm{ZnSt}_{2}$ has proper long-term thermal stability (43 $\mathrm{min}$ ) and excellent initial color.

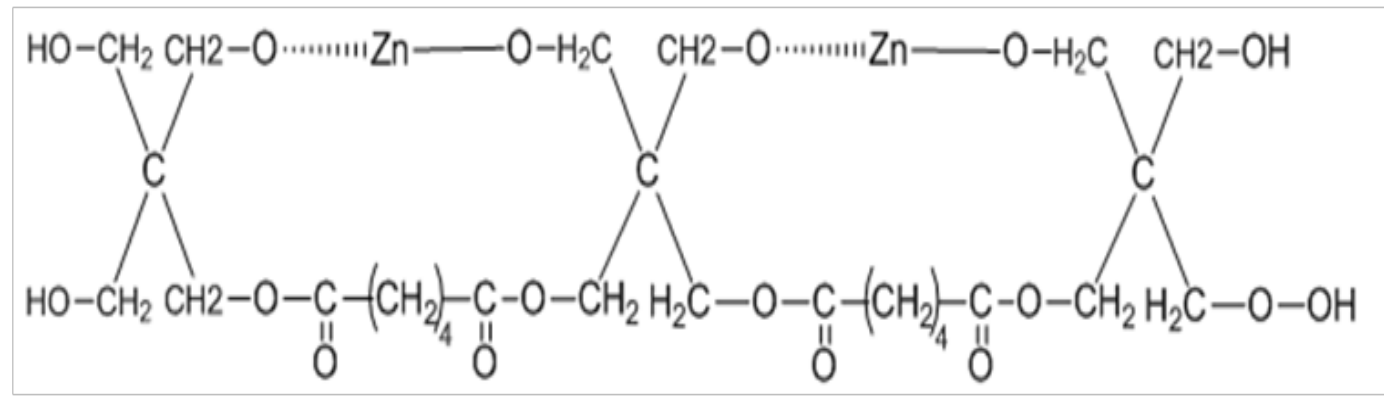

Figure 2 The structure of the PAE-Zn. 


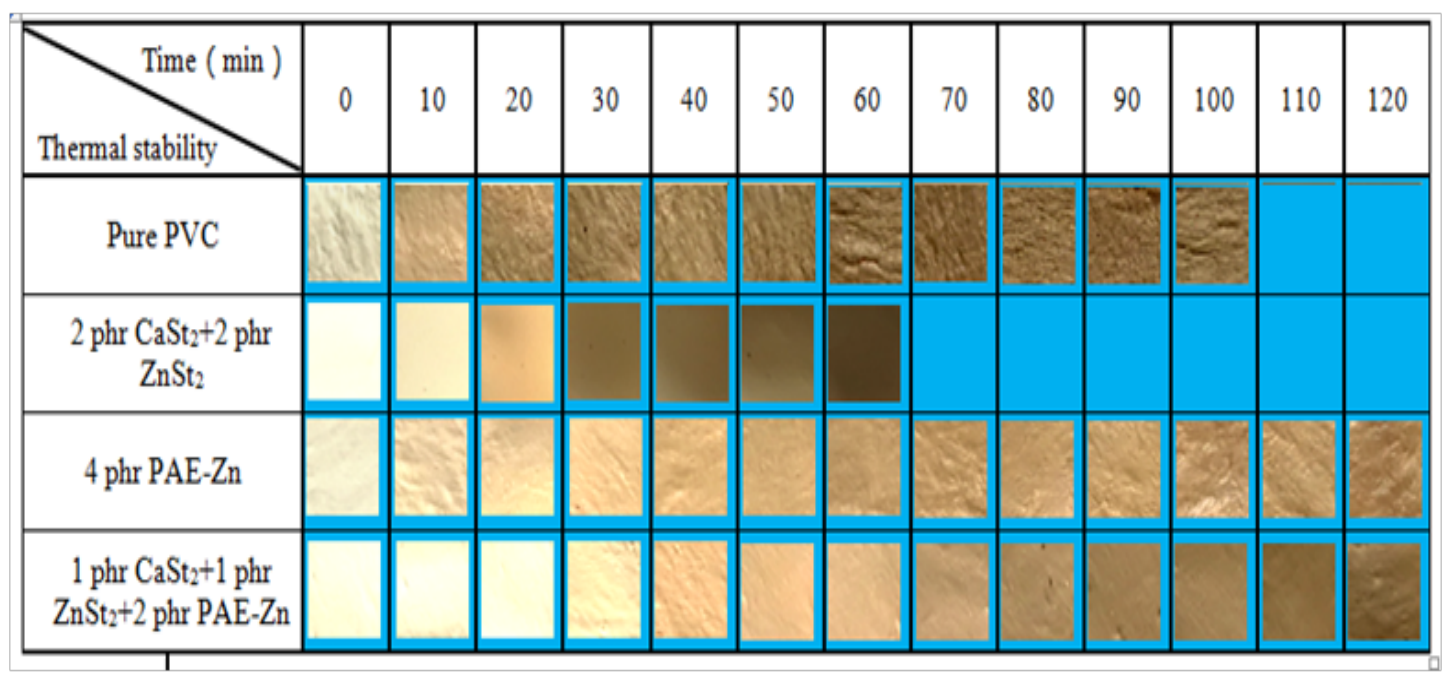

Figure 3 Color evolution of PVC samples with different thermal stabilizers under $180^{\circ} \mathrm{C}$.

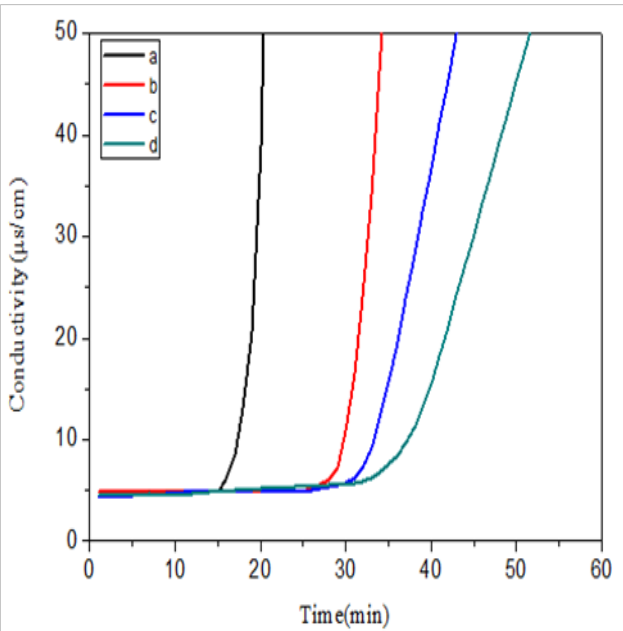

Figure 4 Change of conductivity of aqueous solution with respect to time at $180^{\circ} \mathrm{C}$ for PVC without or with different additives.

A: Pure PVC, B: Ca/ZnSt ${ }_{2}, C: C a / Z n S t_{2}+P A E-Z n, D: P A E-Z n$

\section{Conclusion}

In this paper, PAE-Zn was synthesized and its performance as PVC thermal stabilizers was tested through thermal aging and conductivity tests. Furthermore, the synergistic effect of PAE-Zn and PAE-Zn/ $\left(\mathrm{Ca} / \mathrm{ZnSt}_{2}\right)$ as PVC thermal stabilizers was also studied. The results showed that PVC stabilized with PAE-Zn had remarkable longterm thermal stability. The PVC stabilized with the mixture of PAE$\mathrm{Zn}$ and $\mathrm{Ca} / \mathrm{ZnSt}_{2}$ had excellent initial color and long-term stability, which could be attributed to the strong synergism between PAE-Zn and $\mathrm{ZnSt}_{2}$ due to the hydroxyl groups. PAE- $\mathrm{Zn}$ could chelae $\mathrm{ZnCl}_{2}$ to restrain "zinc-burning".

\section{Acknowledgements}

The authors gratefully acknowledge the support of the University Research Program of Shandong Provincial Department of Education (No.J16LC24), SDUT \& Zibo City Integration Development Project (NO. $=2016 Z B X C 057)$, and the National Natural Science Foundation of China (NO. 51574160, NO.21506118).

\section{Conflict of interest}

The author declares no conflict of interest.

\section{References}

1. Fu M, Li D, Liu H, et al. Journal of Applied Polymer Science. 2016;23:13.

2. Xu S, Li V, Yu X, et al. Study on pentaerythritol-zinc as a novel thermal stabilizer for rigid poly(vinyl chloride). Journal of Applied Polymer Science. 2012;126(2):569-574.

3. Li D, Xie L, Fu M, et al. Synergistic effects of lanthanum-pentaerythritol alkoxide with zinc stearates and with $\beta$-diketone on the thermal stability of poly(vinyl chloride). Polymer Degradation and Stability. 2015;114:52-59.

4. Zhang J, Li D, Fu M, et al. Synergistic effect of adipic acid pentaerythritol ester with calcium and zinc stearates on poly(vinyl chloride) thermal stability. Journal of Vinyl and Additive Technology. 2016;22(3):293-299.

5. Yousif E, Salimon J, Salih N, et al. New stabilizers for PVC based on some diorganotin(IV) complexes with benzamidoleucine. Arabian Journal of Chemistry. 2016;9(Suppl 2):S1394-1401.

6. Li S, Yao Y. Effect of thermal stabilizers composed of zinc barbiturate and calcium stearate for rigid poly(vinyl chloride). Polymer Degradation and Stability. 2011;96(4):637-641.

7. Xie L, Li DG, Zhang J. The effect of pentaerythritol-aluminum on the thermal stability of rigid poly(vinyl chloride). J Appl Polym Sci. 2013;130(5):3704-3709.

8. ISO 305-1990(E) Plastics determination of thermal stability of poly(vinyl chloride), related chlorine-containing homopolymers and copolymers and their compounds-discoloration method. Thermoplastic materials. 1990. p. 1-4.

9. Liu H, Li D, Li R, et al. et al. Journal of Vinyl and Additive Technology. 2017;23:DOI:10. 1002/vnl.

10. Luis J, Gonzalez O, Martin A, et al. Effect of Di(2-ethyl hexyl phthalate)/ epoxidized soybean oil and calcium stearate/zinc stearate ratios on the tensile properties of plasticized PVC formulations. a study for calcium stearate rich formulations. Macromol Symp. 2009;283-284(1):211-222.

11. Hunge YM, Mahadik MA, Moholkar AV, et al. Photoelectrocatalytic degradation of oxalic acid using $\mathrm{WO}_{3}$ and stratified $\mathrm{WO}_{3} / \mathrm{TiO}_{2}$ photocatalysts under sunlight illumination. Ultrason Sonochem. 2017;35(Part A):233-242. 
12. Hunge YM. Sunlight assisted photoelectrocatalytic degradation of benzoic acid using stratified $\mathrm{WO}_{3} / \mathrm{TiO}_{2}$ thin films. Ceram Int. 2017;43(13):10089-10096.

13. Hunge YM. Photoelectrocatalytic degradation of 4-chlorophenol using nanostructured $\alpha-\mathrm{Fe}_{2} \mathrm{O}_{3}$ thin films under sunlight illumination. J Mater Sci: Mater Electron. 2017;28(15):11260-11267.
14. Hunge YM, Mahadik, Moholkal AV, et al. Appl Surf Sci. 2017;420:761 